\title{
A pesquisa no ensino, sobre o ensino e sobre a reflexão dos professores sobre seus ensinos*
}

\author{
Anna Maria Pessoa de Carvalho \\ Universidade de São Paulo
}

\section{Resumo}

Este texto busca mostrar o trabalho desenvolvido no LaPEF (Laboratório de Pesquisa e Ensino de Física), no qual professores do ensino fundamental e médio que vêm trabalhando conosco no contexto dos projetos Fapesp/Escola Pública, pesquisadores que fazem seus mestrados e doutorados e professores da Faculdade de Educação da USP desenvolvem pesquisas no ensino, sobre o ensino e sobre a reflexão dos professores sobre seus ensinos, isto é, sobre formação de professores. Essas três modalidades de pesquisa foram se desenvolvendo a partir da seguinte questão: como o ensino que planejamos, com os pressupostos teóricos que escolhemos, baseados em resultados de pesquisas que já realizamos, estão modificando os alunos?

Os problemas que dão origem às pesquisas no ensino são percebidos pelos professores durante as aulas nas escolas públicas e depois são debatidos e transformados em questões de investigação, por esse mesmo grupo, em discussões coletivas no LaPEF. As pesquisas sobre o ensino estão sendo elaboradas por mestrandos e doutorandos a fim de verificar algumas variáveis importantes para o desenvolvimento desse ensino. A diferença fundamental entre esses dois tipos de pesquisas não está em quem a faz, mas nos objetivos que pretendem alcançar. As pesquisas sobre a reflexão dos professores sobre o ensino abordam a problemática da formação continuada dos professores.

Esse artigo pretende enfocar como esses três níveis de investigações se inter-relacionam, quais as semelhanças e diferenças entre eles, descrevendo principalmente os objetivos de cada um dos grupos e como esses definem diferentes problemas com distintas estruturas de coleta e análise de dados.

\footnotetext{
Correspondência:

Anna Maria Pessoa de Carvalho Faculdade de Educação (EDM)

Universidade de São Paulo e-mail: ampdcarv@usp.br

* Trabalho parcialmente financiado pela Fapesp e CNPq.
}

\section{Palavras-chave}

Pesquisa no ensino e sobre o ensino - Pesquisa na formação de professores - Interação universidade/escola pública. 


\section{The research in teaching, on teaching and on the teachers' reflection about their teaching*}

Anna Maria Pessoa de Carvalho

University of São Paulo

Correspondence:

Anna Maria Pessoa de Carvalho

Faculdade de Educação (EDM)

Universidade de São Paulo

e-mail: ampdcarv@usp.br

\section{Abstract}

This text expounds the work carried out at the LaPEF Laboratory for the Research and Teaching of Physics - where elementary and high school teachers which have been working with us in projects of the FAPESP/Public School program, graduate students, and teachers from the Faculty of Education of the University of São Paulo develop research in teaching, on teaching and on the teachers' reflection about their teaching, i.e., about teachers' education. Those three lines of research evolved from the following question: How does the teaching we plan, with the theoretical assumptions we make, and based on the results of research we have carried out, modifies the students?

The problems that originate our research in teaching are perceived by teachers in the classroom at public schools, and then debated and transformed into research issues by that same group in collective discussions at LaPEF. Research on teaching is developed by master and doctoral candidates who investigate important variables for the development of such teaching. The fundamental difference between these two kinds of research is not who carries them out but the objectives they seek. Research on the teachers' reflection about their teaching focuses on the issues of teachers' continuing education.

This article deals with the questions of how those three levels of investigation related to each other, and what are their differences and similarities, mainly by describing the objectives of each of those groups and how they define different problems, each with their particular structure of gathering and analyzing data.

\section{Keywords}

Research in teaching - Research on teaching - Teacher Education - University-Public School interaction. 
Como todos os grupos das universidades brasileiras que trabalham com formação inicial de professores, fomos incitados a oferecer cursos de formação continuada aos professores das redes oficiais, uma vez que as reformas introduzidas pelos órgãos oficiais para o ensino fundamental e médio propuseram diretrizes bastante inovadoras para as escolas. Além disso, o poder público está bastante consciente do papel essencial que os professores desempenham na renovação curricular (Cronin-Jones, 1991; Mumby; Russel, 1998) e tem presente que sem a aplicação de recursos, principalmente na área de formação de professores, as escolas não irão se modificar.

Por outro lado, nosso laboratório - o Laboratório de Pesquisa e Ensino de Física - tem como hipótese que, para obtermos uma mudança conceitual, atitudinal e metodológica nos professores, um dos principais aspectos da formação continuada deve proporcionar a estes condições que os levem a investigar os problemas de ensino e aprendizagem que são colocados por sua própria atividade docente (Gil-Perez et al., 2000; Maiztegui et al., 2000). Com essa diretriz organizamos cursos (de Física para o nível médio e de Conhecimento Físico para o fundamental), cujos objetivos gerais foram:

a) Favorecer a vivência de propostas inovadoras e a reflexão crítica explícita das atividades de sala de aula

Um problema que encontramos em nossas investigações diz respeito à dificuldade do professor em realizar mudanças na "sua didática" (Carvalho, 1999). 0 ensino baseado em pressupostos construtivistas exige novas práticas docentes e discentes não usuais na nossa cultura escolar. Introduz um novo am-biente de ensino e de aprendizagem, que apresenta dificuldades novas e insuspeitadas ao professor. Ele precisa sentir e tomar consciência desse novo contexto e do novo papel que deverá exercer em classe.

Essas transformações não são tranqüilas. Há inúmeras resistências às mudanças. Os nossos cursos devem criar condições para o envolvimento dos professores participantes em atividades de ensino que sejam problemáticas para seus alunos. Tais atividades, além de possibilitar a vivência de propostas pedagógicas inovadoras, fazem com que os professores se inteirem dos detalhes que essas inovações apresentam. A discussão coletiva, durante o curso, das dificuldades surgidas e do novo papel desempenhado por professores e alunos leva os participantes a um melhor entendimento destas propostas.

\section{b) Problematizar a influência no ensino das} concepções de Ciências, de Educação e de Ensino de Ciências que os professores levam para a sala de aula

A literatura tem mostrado a força das concepções epistemológicas dos professores sobre a natureza da ciência que ensinam, de suas concepções alternativas sobre ensino e da forma como os alunos aprendem e a influência dessas representações nas decisões sobre o ensino e nas práticas docentes (Anderson; Belt, 1987; Hewson; Hewson, 1987; Brickhouse, 1989; Geddis, 1991; Carvalho; Gil, 1993; Glasson; Lalik, 1993; Trivelato, 1993).

Em nossos cursos, essas discussões tornam-se presentes quando debatemos acerca da necessidade de planejar, desenvolver e avaliar atividades de ensino que contemplem a construção-reconstrução das idéias dos alunos referentes às noções cientificamente aceitas e ao papel do professor nessas atividades. Construímos, com os professores, atividades de história das ciências, problemas e questões abertas; investigações no laboratório; demonstrações investigativas e utilização de multimídia visando a discussão das concepções de ciências e de ensino. A discussão dessas atividades nos leva, invariavelmente, a um questionamento das visões simplistas do processo pedagógico de ensino das Ciências, usualmente centradas no modelo transmissão-recepção e na concepção empirista-positivista de Ciências (Silva; Schnetzler, 2000).

A estrutura ideal desses cursos deve compreender uma aula de 3 a 4 horas por semana 
durante um ano letivo (120 horas), possibilitando assim um estreito relacionamento entre 0 referencial teórico e a prática dos professores em sala de aula, criando condições para a experimentação de atividades propostas no curso, reflexão e problematização da ação docente e uma discussão coletiva sobre a relação tão óbvia, mas tão difícil de ser observada, do ensinar e do aprender. A necessidade de questionar essas concepções junto aos professores tem-se mostrado como um fator bastante relevante na formação dos mesmos. (Tabachnik; Zeichner, 1999; Hewson et al., 1999).

c) Introduzir os professores na investigação dos problemas de ensino e aprendizagem de Ciências tendo em vista superar o distanciamento entre contribuições da pesquisa educacional e a sua adoção

Incentivamos a experimentação, pelos professores, dessas atividades em suas aulas e o registro destas (em vídeo) como material de discussão e reflexão coletiva dos processos de ensino e aprendizagem, concebendo então a prática pedagógica cotidiana como objeto de investigação, como ponto de partida e de chegada de reflexões e ações pautadas na articulação teoriaprática (Carvalho; Gil, 1993; Carvalho; Gonçalves, 2000). Procuramos assim criar condições para que o professor seja também o pesquisador de sua própria prática pedagógica.

\section{O curso de Termodinâmica para os professores do ensino médio e o curso de Conhecimento Físico para as professoras do ensino fundamental}

Quando planejamos o curso para os professores do nível médio escolhemos trabaIhar com a Termodinâmica, pois, sobre esse conteúdo, já tínhamos realizado no LaPEF investigações em que testamos em sala de aula atividades de História das Ciências (Carvalho;
Castro, 1995), laboratório aberto (Teixeira, 1993) e discussões relacionadas com as novas tecnologias (Silva, 1995). Tínhamos, assim, algumas atividades já testadas e vídeos de sala de aula que serviam para discussões. Incluímos a apresentação dos conceitos espontâneos já estudados sobre esse tópico (Driver et al., 1989; Teixeira, 1993). Além disso, discutimos com os professores a dificuldade desse ensino no nível médio, quando os conceitos a serem ensinados foram descritos dentro do modelo do calor como calórico e a necessidade atual das discussões fenomenológicas enfocar calor como energia em transformação.

Quando planejamos o curso para as professoras do ensino fundamental e para as assistentes técnico-pedagógicas (ATP), propusemo-nos a mostrar que as crianças (de 7 a 10 anos) conseguem resolver problemas físicos chegando até a explicações causais dos fenômenos apresentados (Carvalho et al., 1998). Outro aspecto considerado foi que as atividades que planejamos, quando propostas em sala de aula, eram bastante divertidas para os alunos e os ajudavam no desenvolvimento da linguagem oral e escrita. Tínhamos também vídeos das atividades com professoras e alunos. No curso trabalhamos com as professoras tanto com o conteúdo físico quanto com o pedagógico, sempre partindo da vivência trazida por elas, de suas próprias aulas, e da reflexão sobre suas experiências. As professoras desse nivel são abertas às inovações pedagógicas, mas infelizmente têm muito receio de enfrentar aulas de Ciências cujo tema sejam experiências investigativas de física. A falta desse conteúdo em seus cursos de formação cria resistências difíceis de vencer. Esse obstá-culo foi superado quando conseguimos que algumas delas aplicassem em suas próprias classes as atividades, as gravassem em vídeo e as apresentassem para as colegas. Essas discussões foram muito frutíferas, pois mostraram uma aula alegre, com muita participação dos alunos e, por meio de seus escritos, as professoras puderam verificar a aprendizagem dos alunos. A discussão mais difícil 
desse curso diz respeito à mudança de paradigma no conceito de avaliação dos alunos (Carvalho; Gonçalves, 2000).

Apesar de as duas propostas de ensino que estamos desenvolvendo no LaPEF - o de Termodinâmica e o de Conhecimento Físico para o ensino fundamental - serem planejadas para diferentes graus de ensino, elas têm muitas coisas em comum. Ambas estão dentro de uma linha cons-trutivista tendo por base os mesmos referenciais teóricos e a mesma concepção de ensino de Ciências: propõem que a aprendizagem se inicie a partir de questões a serem resolvidas pelos alunos. A origem das atividades planejadas por ambas propostas foi nossas dissertações de mestrado e teses de doutorado, que testaram em salas de aula inovações didáticas, tanto para o ensino médio quanto para as primeiras séries do fundamental, como mostramos nos parágrafos anteriores.

Sem dúvida alguma, o nível de sistematização, de matematização e de aprofundamento no conteúdo específico é bem diferente para cada uma das propostas. Entretanto, ambas foram planejadas da perspectiva de que a ciência apresenta uma linguagem própria e uma forma particular de ver o mundo, e familiarizar-se com suas práticas pode ser considerado como uma espécie de aculturação (Driver; Newton, 1997). Nosso ensino pretende introduzir os estudantes em uma nova linguagem, a linguagem científica escolar, apreciando sua importância para dar novo sentido às coisas que acontecem ao seu redor, entrando em um mundo simbólico que representa o mundo real.

\section{Os projetos de pesquisa que se originaram dos cursos}

Quando o curso de Termodinâmica terminou, seis professores quiseram continuar trabalhando conosco com o objetivo de testar, de forma sistemática, as idéias debatidas durante o curso e o planejamento elaborado como tra- balho final. Investigar se a mudança no ensino iria produzir uma melhoria na qualidade da aprendizagem de seus alunos tornou-se uma questão vital.

Planejamos um projeto de pesquisa com a finalidade de estudar a melhoria da qualidade do ensino de Física nas classes desses seis professores. Esse projeto foi escrito pelos professores e apresentado à Fapesp, pois precisávamos de bolsas para os mesmos, material de laboratório e infra-estrutura para as escolas. 0 projeto foi aprovado para ser desenvolvido em um ano, com possibilidade de continuação condicionada à aprovação do relatório final de cada etapa e das novas propostas de trabalho. Estamos atualmente no quarto ano e agora são sete os professores bolsistas que participam desse projeto.

0 trabalho dos professores está sendo desenvolvido em suas escolas, mas também tínhamos, e continuamos a ter, reuniões semanais de três horas no LaPEF, nas quais os professores planejam coletivamente suas aulas; criam atividades de investigação reconstruindo e adaptando o material didático existente; preparam material de avaliação; questionam suas práticas docentes mediante uma reflexão explícita sobre suas aulas e, principalmente, tomam consciência dos problemas de ensino e aprendizagem que aparecem em suas aulas e que merecem ser investigados. Todas as reuniões, no seu primeiro ano, foram gravadas em áudio.

Exatamente o mesmo processo aconteceu com as assistentes técnico-pedagógicas (ATP). Quando o curso terminou, fomos procuradas por um grupo de cinco ATPs com uma proposta de trabalho conjunto. Discutimos um projeto de pesquisa, que se desenvolveria em cinco escolas de ensino fundamental e o apresentamos à Fapesp. Esses passos são importantes para o LaPEF, pois não só é a única maneira de se obter bolsas para as ATPs e material de laboratório para as escolas, como também é o reconhecimento institucional desse tipo de investigação. 0 projeto foi aprovado por um ano, com possibilidade de continuação a par- 
tir do relatório apresentado e das novas propostas de trabalho. ${ }^{2}$

Acabamos o segundo ano de pesquisa, tivemos nosso relatório aprovado e mais três bolsas, o que significa que iremos trabalhar com mais três escolas do primeiro ciclo do ensino fundamental.

Como no projeto de Termodinâmica, as ATPs têm o seu trabalho nas escolas e as reuniões semanais no LaPEF.

\section{A Integração das pesquisas realizadas pelos professores e ATPs na dinâmica do LaPEF}

Estamos tentando integrar os trabalhos desenvolvidos no nosso Laboratório - as pesquisas dos orientandos para obtenção de seus mestrados e doutorados com aquelas desenvolvidas pelos professores de ensino médio, pelas ATPs e professoras que trabalham no ensino fundamental. Temos as condições ideais para nos aprofundarmos nas pesquisas em ensino de Física, pois:

- Temos sob nossa coordenação dois grandes projetos que estão se desenvolvendo nas escolas públicas cujos professores e ATPs estão trabalhando conosco, reunindo-se no LaPEF uma vez por semana.

- Temos um grupo de mestrandos e doutorandos que nos escolheram por nossa linha de pesquisa e estão interessados em investigar aspectos relacionados ao ensino de Física e formação de seus professores.

- Temos principalmente a nossa grande questão: 0 ensino que planejamos, com os pressupostos teóricos que escolhemos, a partir dos resultados de pesquisas que já realizamos, estão realmente modificando os alunos dos cursos fundamental e médio?

Apesar de todos estarem interessados no mesmo fenômeno - o ensino e a aprendizagem nas aulas dadas nos cursos fundamental e médio (de Física e de Conhecimento Físico) - o olhar de cada um dos grupos é muito diferente. 0 interesse de pesquisa dos professores está bastante direcionado à aprendizagem de seus alunos (aprenderam ou não? Quantos aprenderam? Aprenderam tudo o que ensinamos?), os pesquisadores do laboratório estão preocupados em entender como se dá a relação ensino/aprendizagem (p. ex., o papel da argumentação de alunos e professores) e, também, em estudar a própria formação continuada desses professores.

$\mathrm{Na}$ verdade, em nosso Laboratório podemos distinguir três tipos de investigações: as investigações no ensino, realizadas pelos professores do curso médio e as ATPs; as sobre o ensino, realizadas por parte dos pósgraduandos com base em dados retirados nas salas de aulas desses professores; e as sobre reflexões dos professores sobre o seu ensino, realizadas por aqueles que estão estudando os problemas da formação (continuada) de professores.

\section{As pesquisas realizadas pelos professores no seu ensino}

As investigações no ensino são, no meu ponto de vista, paralelas ao que Schön (1987) denominou reflexão no ensino. Os problemas que dão origem a essas pesquisas são percebidos durante as aulas e, em seguida, são debatidos e transformados em questões pelo grupo de professores, quando refletem sobre os seus próprios trabalhos em sala de aula durante as discussões coletivas no Laboratório. Vamos exemplificar esse processo com o desenvolvimento do Projeto de Termodinâmica.

No primeiro ano do Projeto o objetivo principal dos professores foi vivenciar a proposta de um ensino por investigação no conteúdo de Termologia e Termodinâmica e verificar a mudança de qualidade do aprendizado dos alunos incluindo a mudança de atitude destes diante do ensino de Física. Para isso foi preci-

2. Este projeto está sendo coordenado pela professora doutora Maria Lúcia Vital dos Santos Abib. 
so construir e adaptar um número maior de atividades de ensino ${ }^{3}$ e, principalmente, criar instrumentos de avaliação que fossem coerentes com as inovações didáticas (Darsie, 1996).

A discussão coletiva sobre o que significava uma "mudança de qualidade do aprendizado dos alunos", sobre quais os indicadores desta qualidade e como poderiam ser obtidos dados que mostrassem a evolução do aprendizado de seus alunos foi extremamente interessante e produtiva. Eles inicialmente discutiram a importância de verificar a evolução dos alunos nos seguintes pontos: a aprendizagem dos principais conceitos ensinados; o entendimento desse conteúdo nas diversas linguagens da física (fenomenológica, gráfica e matemática) e suas traduções; a participação e o envolvimento dos alunos nas atividades de investigação aberta, de demonstrações investigativas e nas discussões dos textos históricos.

Essas discussões foram sistematizadas em uma questão:

- Como medir a mudança de qualidade do aprendizado dos alunos incluindo a mudança de atitudes desses alunos diante do ensino de Física?

- Para resolver esse problema duas outras questões precisaram ser respondidas com antecedência:

- Quais as competências e habilidades indicadas nos PCNs que os alunos podem adquirir em cada uma das atividades propostas durante o curso?

- Como sistematizar os instrumentos de avaliação de modo que os dados possam apresentar compatibilidade entre as diversas atividades?

A volta aos referenciais teóricos foi necessária mostrando que quando os professores estão em um clima de investigação, tendo um problema prático explícito para resolver, buscam a teoria para auxiliar na sua resolução (assim como outros cientistas).

Estas e outras questões estão sendo trabalhadas pelo grupo, ${ }^{4}$ mas o que gostaria de ressaltar neste artigo são as finalidades dessas pesquisas realizadas no ensino e, conseqüentemente, a metodologia empregada.

Os professores, ao proporem mudanças em suas práticas pedagógicas, querem relacioná-las de imediato com a aprendizagem de seus alunos. Eles querem saber se a classe está aprendendo, se a classe está se envolvendo cognitiva e afetivamente com o seu ensino. Essa constatação vai ao encontro dos resultados das pesquisas internacionais de formação de professores de Ciências que identificaram a melhoria da qualidade da aprendizagem do aluno como o fator principal para que os professores mudassem sua prática em sala de aula (Bell, 1998). Esse é um tipo de pesquisa que visa uma melhoria profissional.

0 importante para o professor que tem um curso pela frente é a análise quantitativa de cada variável definida qualitativamente. 0 enfoque principal dado às questões é sempre o quantitativo, isto é, a preocupação fundamental é o “quanto”. Por exemplo, para a questão: "como os alunos se desenvolvem nas aulas de demonstrações investigativas?", o direcio-namento dado foi "quantos alunos alcançam os conceitos, habilidades e competências definidos para essas aulas?".

Tendo uma pergunta quantitativa, consequentemente a metodologia empregada para o desenvolvimento dessas pesquisas se enquadra no referencial quantitativo. Mesmo quando os dados são obtidos com instrumentos utilizados nas investigações qualitativas, como os diários reflexivos (Darsie, 1998; Dana; Tippins, 1998), estes

3. Esse material foi publicado em forma de um livro dirigido aos seus colegas, professores do curso médio, Termodinâmica: um ensino por investigação (Carvalho et al., 1999).

4. Alguns desses resultados foram apresentados pelos professores no III ENPEC, Encontro Nacional de Pesquisa em Educação em Ciências, Atibaia, 7 a 10 de Novembro de 2001. 
são categorizados e trabalhados quantitativamente.

\section{As pesquisas sobre o ensino dos professores}

As pesquisas sobre o ensino estão sendo elaboradas por mestrandos e doutorandos, procurando estudar o ensino que está sendo realizado, verificando algumas variáveis importantes para o desenvolvimento desse.

A diferença fundamental entre estes dois tipos de pesquisas não é quem a faz, mas os objetivos que pretendem alcançar. As duas constroem seus problemas, e conseqüentemente seus dados, nas mesmas aulas. Entretanto, as pesquisa sobre o ensino pretendem estudar 0 "como" para chegar ao "porquê" os alunos aprendem, alcançando os conteúdos, habilidades e competências determinadas nas pesquisas no ensino.

Outra diferença está na forma como são elaborados os problemas. Enquanto no primeiro tipo os questionamentos saem da prática, da necessidade intrínseca do professor de querer saber se o seu ensino realmente ensina, no segundo caso os problemas têm uma grande influência da literatura em pesquisa em ensino de ciências, das revisões bibliográficas sobre outras pesquisas já realizadas e, portanto, da comunidade científica.

0 pesquisador só vai a campo com o problema bem delimitado, sabendo o que vai observar. A maior parte é estudo de casos, em que um tipo de atividade de ensino é pesquisada; por exemplo, o ensino por meio das demonstrações investigativas, dos laboratórios abertos ou da introdução de textos históricos. Aprofunda-se nas relações professor/aluno/conteúdo, aluno/aluno/conteúdo. Agora o que queremos observar é a qualidade das interações.

Esse tipo de investigação se enquadra em um referencial qualitativo, sendo que a coleta de dados quase sempre tem como peça central as gravações das aulas dadas, os traba- lhos dos professores e de seus alunos.

Vamos mostrar alguns exemplos de pesquisas que estamos realizando no Laboratório. Sobre o conjunto de aulas de demonstrações investigativas, que já sabemos que os alunos gostam, participam e aprendem, estamos procurando responder as seguintes questões: "qual o papel da linguagem do professor na construção do conhecimento de seus alunos?", e "quais as condições de ensino que possibilitam as argumentações dos alunos?".

Um outro conjunto de aulas que modificam o entendimento do que são as Ciências são as atividades de história da ciência. Algumas perguntas foram elaboradas com a finalidade de entender melhor a introdução dos textos históricos no ensino médio. Gostaríamos de ter respostas às seguintes questões: "os estudantes conseguem perceber a ciência como uma construção quando participam destas atividades?", “como se dá a interação texto/ aluno(s)/professor?", "qual o papel do professor na condução destas atividades?".

No Projeto de Conhecimento Físico, desenvolvido nos primeiros anos da escola fundamental, temos inúmeras questões. Entretanto, estamos atualmente procurando responder a estas: "as atividades de Conhecimento Físico proporcionam um aprimoramento nas linguagens escrita e oral dos alunos?", e "qual a influência dos aspectos afetivos no desenvolvimento dessas atividades?". Para esses trabalhos estamos gravando vídeos com grupos de alunos de $3^{\text {a }}$ série durante uma seqüência de cinco atividades e analisando as gravações, os trabalhos escritos dos alunos, e entrevistando os professores e os próprios alunos.

\section{A pesquisa sobre a reflexão dos}

\section{professores sobre os seus ensinos}

Procuramos gravar em vídeo todos os cursos que oferecemos aos professores. Temos assim muitos materiais em que, nas discussões sobre as atividades propostas por nossa equipe, os professores, ao criticá-las 
positiva ou negativamente, falam sobre suas aulas, descrevem suas realidades e algumas vezes até trazem vídeos de suas classes. Esse material é muito rico, pois a partir de sua análise, podemos verificar as concepções de ensino, de aprendizagem e de ciências trazidas pelo professor e sua evolução durante os cursos. Naturalmente, todos esse vídeos só se transformam em dados para nossas pesquisas com a autorização, por escrito, do professor.

Uma outra fonte de dados para as pesquisas sobre formação de professores são as gravações das reuniões dos professores no LaPEF. Nessas reuniões semanais o trabalho central tem sido (pelo menos nos primeiros dois anos) o de elaborar material didático, vivenciá-lo, reelaborá-lo e refletir coletivamente sobre essa ação tendo por foco a aprendizagem dos alunos. Enfim, um trabalho de reflexão global sobre uma experiência didática em todos os seus aspectos.

As pesquisas sobre a reflexão dos professores sobre o ensino estão verificando algumas facetas importantes em relação às propostas de ensino que estão sendo desenvolvidas, mas abordando principalmente a problemática da formação continuada dos(as) professores(as) que fazem parte de nossos projetos. São investigações qualitativas, quase sempre estudos de caso, nos quais, além das gravações, obtém-se a triangulação dos dados por meio de entrevistas com os professores dos projetos, seus diretores e colegas que lecionam nas mesmas escolas.

Estamos atualmente procurando responder às seguintes questões: "quais os conflitos, dificuldades e elementos estimuladores que aparecem para um grupo de professores que querem implementar uma proposta inovadora de ensino em suas escolas?", "como conseguem superar essas barreiras?", e "como os professores concebem os processos de ensino e de aprendizagem em Ciências? De que maneira suas concepções articulam-se com suas práticas de sala de aula e com o contexto no qual atuam?".

\section{O intercâmbio entre as pesquisas}

Esses três tipos de pesquisas, que se realizam simultaneamente no LaPEF, não só se alimentam entre si como também são fontes diretas para a melhoria do ensino, o que na verdade é o mais importante.

A pesquisa no ensino indica as melhores atividades e os melhores professores para que a pesquisa sobre o ensino investigue o "que" está acontecendo e o "porquê" aconteceu. Esses dados e essas interpretações são discutidos por todo o grupo do Laboratório, influenciando diretamente não só o professor que foi o agente da pesquisa, como todo o grupo.

Os resultados das pesquisas sobre a reflexão dos professores sobre os seus ensinos também são passados para os professores e discutidos pelo grupo, pois na verdade eles são os agentes dessas pesquisas.

A divulgação dos resultados dessas pesquisas se faz também de forma diferenciada. As investigações na escola representam pesquisas que têm a finalidade de um desenvolvimento profissional e mostram uma relação mais direta entre ensino e aprendizagem. 0 grupo de professores responsável por esses trabalhos prefere sistematizá-los em livros dirigidos a seus colegas do que apresentá-los em congressos. Quando isto é feito, é estritamente para agradar e participar em igualdade com o restante do Laboratório e não por necessidade intrínseca dessa divulgação.

As pesquisas sobre a escola e sobre a reflexão dos professores, ao contrário, são pesquisas feitas por mestrandos e doutorandos, visando à produção de conhecimento científico, dentro dos referenciais definidos pela sociedade científica. Assim, sua divulgação também se dá nos encontros - congressos e simpósios - organizados pelas sociedades científicas. Os resultados desses trabalhos são pu- 
blicados primeiramente em atas de congressos e, depois de uma revisão, em revistas especializadas. Somente alguns, depois de várias modificações, são transformados em livros, quase sempre dirigidos a outros pesquisadores.

Apesar de todas as diferenças, esses três segmentos da pesquisa educacional precisam existir em conjunto, em um trabalho realizado coletivamente, pois todos têm um objetivo em comum: a melhoria de nossas escolas.

Temos de ter consciência que esses trabalhos são elaborados por grupos diferentes e dirigidos para públicos diferentes. Não há e não deve haver predomínio de um tipo sobre o outro, todos são extremamente importantes para o desenvolvimento educacional do país.

\section{Referências bibliográficas}

ANDERSON, C.W.; BELT, B.L. A social constructivist analysis on classroom science teaching. In: ProceEdings of THE INTERNATIONAL SeminaR on Misconceptions and Educational Strategies in Science and Mathematics, 2. New York, 1987. v.2, p.11-24.

BELL, B. Teaching development in science education. In: FRASER, B.J.; TOBIN, K.G. (Ed.) International Handbook of Science Education, 1998. p. 681-693.

BRICKHOUSE, N. W. The teaching of the philosophy of science in secondary classrooms: case study of teachers' personal theories. International Journal of Science Education, London, v.11, n.4, p.437-449, 1989.

CARVALHO, A.M.P. Uma Investigação na formação continuada dos professores: a reflexão sobre as aulas e a superação de obstáculos. In: Encontro Nacional de Pesquisa em EducaçÃo em Clências, 2., 1999, Valinhos. Atas.Valinhos: ABRAPEC, 1999.

CARVALHO, A.M.P.; VANNUCCHI, A.I.; BARROS, M.A.; GONÇALVES, M.E.; REY, R.C. Ciências no ensino fundamental: o conhecimento físico. São Paulo: Scipione, 1998.

CARVALHO, A.M.P. et al. Termodinâmica: um ensino por investigação. São Paulo: FEUSP/CAPES, 1999.

CARVALHO, A.M.P.; CASTRO, R. The history approach in teaching: analysis of an experience. Science Education, Dordrecht, v.4, n.1, 1995.

CARVALHO, A.M.P.; GIL-PÉREZ, D. Formação de professores de ciências. São Paulo: Cortez, 1993.

CARVALHO, A.M.P.; GONÇALVES, M.E.R. Formação continuada de professores: 0 vídeo como tecnologia facilitadora da reflexão. Cadernos de Pesquisa, São Paulo, n.111, p.71-88, 2000.

CRONIN,-JONES L.L. Science teaching beliefs and their influence on curriculum implementation: two case studies. Journal of Research in Science, New York, v.38, n.3, 235-250,1991.

DANA, T.M.; TIPPINS, D.J. Portfolios, reflection and educating prospective teachers of science. In: FRASER, B.J.; TOBIN, K.G. (Ed.) International Handbook of Science Education. [S.I.: s.n.] 1998. p.719-732, v.2.

DARSIE, M. M. A reflexão na construção dos conhecimentos profissionais do professor em cursos deformação. 1998. Tese (Doutorado). Faculdade de Educação. Universidade de São Paulo, São Paulo, 1998.

DARSIE, M. M. P. Avaliação e aprendizagem. Cadernos de Pesquisa, São Paulo, n.99, p.47-59, 1996.

DRIVE, R.; GUESNES, E.; TIBERGHIEN, A. Ideas científicas en la infancia y la adolescencia. Madrid: Morata/MEC, 1989.

DRIVER, R.; NEWTON, P. Establishing the norms of scientific argumentation in classrooms. In: ESERA ConfERENCE, 1997. Rome. Paper... Rome, 1997.

GEDDIS, A.N. Improving the quality of science classroom discourse on controversial issues. Science Education, New York, v.75, n.2, p.169-183, 1991. 
GIL-PEREZ, D.; CARVALHO, A.M.P. Dificultades para la incorporación a la enseñanza de los hallazgos de la investigación e innovación en didáctica de las ciencias. Educación Química, v.11, n.2, p.244-251, 2000.

GLASSON, G.E.; LALIK, R.V. Reinterpreting the learning cycle from a social constructivist perspective: a qualitative study of teachers' beliefs and practices. Journal of Research in Science Teaching, New York, v.30, n.2, p.187-207, 1993.

HEWSON, P.W.; HEWSON, M.G.A. Identifying conceptions of teaching science. In: ProceEDIngS Of The InTERNATIONAL Seminar on Misconceptions and Educational Strategies in Science and Mathematics, 2. New York: Cornell University, 1987. v.2.

HEWSON, P.W.; TABACHNIK, B.R.; ZEICHNER, K.M.; LEMBERGER, J. Educating prospective teachers of biology: finding, limitation and recommendations. Science Education, New York, v.83, n.3, p.373- 384, 1999

MAIZTEGUI, A.P.; GONZÁLES, E.; TRICÁRICO, H.R.; SALINAS, J.; CARVALHO, A.M.P.; GIL-PEREZ, D. La formación de los profesores de ciencias en la Argentina. Boletín de La Academia Nacional de Educación, Buenos Aires, v.46, p.26-34, 2000.

MUMBY, H.; RUSSEL, T. Epistemology and context in research on learning to teach science. In: FRASER, B.J.; TOBIN, K.G. (Ed.) International Handbook of Science Education, s.n.t.

SCHÖN, D.A. Educating the reflective practitioner. San Francisco: Jossey Bass Inc. Publishers, 1987.

SILVA, D. Estudo das trajetórias cognitivas de alunos no ensino da diferenciação dos conceitos de calor e temperatura. 1995. Tese (Doutorado). Faculdade de Educação. Universidade de São Paulo, São Paulo,1995.

SILVA, L.H. A.; SCHNETZLER, R.P. Buscando o caminho do meio: a "sala de espelhos" na construção de parcerias entre professores e formadores de professores de ciências. Revista Ciências \& Educação, v.6, n.1, p.43-53, 2000.

TABACHINIK, B.R.; ZEICHNER, K.M. Idea and action: action research and the development of conceptual change teaching science. Science Education, New York, v.83, n.3, p.309-322, 1999.

TEIXEIRA, O.P.B. Desenvolvimento do conceito de calor e temperatura: a mudança conceitua. 1993. Tese (Doutorado). Faculdade de Educação, Universidade de São Paulo, São Paulo, 1993.

TRIVELATO, S.L.F. Ciência, tecnologia e sociedade: mudanças curriculares e formação de professores. 1993. Tese (Doutorado). Faculdade de Educação, Universidade de São Paulo, São Paulo, 1993.

Recebido em 25.03.02

Aprovado em 16.09.02

Anna Maria Pessoa de Carvalho é professora titular no Departamento de Metodologia do Ensino e Educação Comparada da Faculdade de Educação da Universidade de São Paulo. Organizou e é a coordenadora do Laboratório de Pesquisa e Ensino de Física no qual mais de trinta professores fizeram seus mestrados e doutorados. 